\title{
Evaluation of peritoneal endometriosis treatment using intralesional acetylsalicylic acid injection in rabbits ${ }^{1}$
}

\author{
Rogério Saad-Hossne ${ }^{\mathrm{I}}$, Adriana Beatriz Barretto ${ }^{\mathrm{II}}$, Juliana Menezes Siqueira ${ }^{\mathrm{III}}$, Rafael Denadai ${ }^{\mathrm{IV}}$ \\ DOI: http://dx.doi.org/10.1590/S0102-865020160040000002 \\ IPhD, Full Professor, Postgraduate Program in General Bases of Surgery, Department of Surgery, Botucatu Medical School (FMB), Universidade \\ Estadual de São Paulo (UNESP), Botucatu-SP, Brazil. Conception, design, intellectual and scientific content of the study; manuscript writing; critical \\ revision; supervised all phases of the study \\ "Fellow Master degree, Postgraduate Program in General Bases of Surgery, Department of Surgery, FMB, UNESP, Botucatu-SP, Brazil. Acquisition \\ and interpretation of data, technical procedures, manuscript writing. \\ IIIMD, Division of Coloproctology, Department of Surgery, FMB, UNESP, Botucatu-SP, Brazil. Technical procedures.

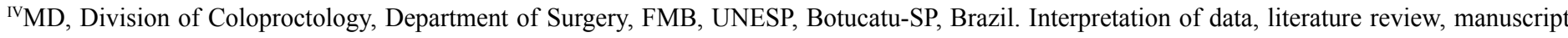 \\ writing, critical revision.
}

\begin{abstract}
PURPOSE: To investigate the efficacy of intralesional 20\% aspirin injection for treatment of experimental peritoneal endometriosis. METHODS: Peritoneal endometriosis was experimentally induced in forty adult nulligravid female rabbits. On day 30 post-endometriosis induction, rabbits were randomly divided to assess early (10 days) and late (20 days) effects of intralesional injection of physiological saline solution (control groups) in comparison to intralesional injection of $20 \%$ bicarbonate aspirin solution (experimental groups) as follows: control group 1 ( 10 days, $n=10$ ); control group 2 (20 days, $n=10)$; experimental group 3 (10 days, $n=10)$; experimental group 4 (20 days, $n=10$ ). Resected tissues, including endometriosis foci, were qualitatively (general morphology and signs of inflammatory cells infiltrate, necrosis and apoptosis) and quantitatively (remaining endometriosis area) assessed by histopathological analysis.

RESULTS: Extensive necrosis, hemorrhage, apoptosis, and fibrosis were observed in the experimental groups 3 and 4 . Groups 1 and 2 presented typical endometrial tissue cysts, respectively. Groups 3 and 4 showed sparse endometrial tissue foci and no endometrial tissue, respectively. Quantitative analysis revealed that aspirin-treated groups 3 and 4 had significantly ( $<<0.05)$ smaller remaining endometriosis area, compared to control groups 1 and 2.
\end{abstract}

CONCLUSION: Intralesional 20\% aspirin injection caused total destruction of peritoneal endometriosis foci in rabbits.

Key words: Aspirin. Endometriosis. Rabbits. 


\section{Introduction}

Endometriosis is an estrogen-dependent chronic inflammatory condition that affects an estimated 176 million women in reproductive age worldwide, and is associated with dysmenorrhea, deep dyspareunia, and infertility ${ }^{1,2}$. Symptoms of endometriosis substantially contribute to disease burden and add substantial cost to society due to reduced economic and personal productivity $^{1,2}$.

Surgical removal of lesions and hormonal suppression are the current therapeutic gold standards for women with endometriosis-associated pelvic pain and/or infertility ${ }^{1-3}$. However, non-surgical intervention is mostly symptomatic, not cytoreductive and surgery is correlated with a high rate of recurrence with variable success and relapse rates according to the different reports ${ }^{1-3}$. Although lesion eradication is considered a fertilityenhancing procedure, benefits on reproductive performance are moderate ${ }^{1-3}$. As a consequence, established pharmacological or surgical approaches are not a feasible option for all patients within the wide clinical spectrum of endometriosis ${ }^{1-3}$.

In this context, emerging pharmacological therapies interfering with the inflammatory condition, hormone responsiveness, cell survival, proliferation, neoangiogenesis, and invasion have been mainly tested in preclinical studies, including humans ${ }^{1,2,4,5}$. In general, these novel medications have been related as uncertain or inefficacious and the unpleasant effects associated with the majority of tested drugs are unacceptable in healthy women affected by a benign condition ${ }^{2,4,5}$. Thus, therapeutic research efforts should focus on identifying and testing welltolerated, low-cost, easily accessible substances capable of acting locally on lesions, without interfering with ovulation, for efficacy in both pain symptoms and infertility ${ }^{6}$.

Over the last decade, our research group ${ }^{7-12}$ has evaluated the cytolytic and antineoplastic potentials of acetylsalicylic acid (aspirin) and its derivatives. Recently, $\mathrm{we}^{12}$ have also demonstrated that intralesional 5\% aspirin injection has an experimental effect on the reduction of peritoneal endometriosis. However, clusters of endometrial tissue were still detected in our previous histological assessments $^{12}$. Based on the collective results from our in vitro (cultured tumor cell systems) and in vivo (animal-implanted tumors/lesions) analyses ${ }^{7-12}$, we hypothesized that injecting $20 \%$ aspirin directly into lesions may totally eliminate endometriosis foci.

Therefore, the present study assessed the therapeutic efficacy of intralesional $20 \%$ aspirin injection using the wellestablished peritoneal endometriosis rabbit model.

\section{Methods}

The experimental protocol was approved by the Research Ethics Board of the Faculty of Medicine, Universidade Estadual de São Paulo (UNESP). All procedures involving animals were performed in accordance with the guidelines on Care and Use of Laboratory Animals by the Institute for Laboratory Animal Research (1996) and the ethical principles of the Brazilian College on Animal Experimentation (COBEA).

\section{Animal housing and anesthesia}

The study was performed as a parallel-group, doubleblind, stratified, randomized controlled animal trial with $1: 1$ allocation ratio.

Forty adult, nulligravid, female New Zealand albino rabbits (6-9 week-old, weighing 2.3-2.5 kg) were housed under $12 / 12 \mathrm{~h}$ light-dark cycles with unrestricted access to standard rabbit chow (Coelhil $\mathrm{R}^{\circledR}$, Socil, Belo Horizonte-MG, Brazil) and water. Animals were fasted six hours prior to tumor inoculation. All surgical procedures were performed under general anesthesia by $3 \%$ sodium pentobarbital ( $30 \mathrm{mg} / \mathrm{kg}$ body weight) intravenous injection ${ }^{12}$.

\section{Induction of peritoneal endometriosis}

Peritoneal endometriotic lesions were surgically induced, as previously described ${ }^{12}$. Briefly, approximately $4 \mathrm{~cm}$ of the right uterine horn was resected via supra-umbilical median laparotomy. Two $5 \times 5 \mathrm{~mm}$ segments of the excised horn were cut and placed in sterile physiological saline solution. The two endometriotic fragments were then transplanted into the most vascularized areas of the peritoneum located to the right and left sides of the middle laparotomy-incision, with the epithelial lining of the segment in apposition to the ventrolateral body wall using absorbable sutures (Ethicon vicryl 6-0; Johnson and Johnson, São José dos CamposSP, Brazil). The laparotomy incision was closed by suturing with non-dissolving sutures (Ethicon mononylon 4-0; Johnson and Johnson, São José dos Campos-SP, Brazil). The surgeon who performed all laparotomies was completely blind to allocations and medications.

\section{Treatment of endometriosis foci}

At 30 postoperative days, when the endometriotic lesions had reached about $2.5 \mathrm{~cm}$ in diameter ${ }^{12}$, rabbits were randomly 
allocated using a computer generated process into experimental $(\mathrm{n}=20)$ and control $(n=20)$ groups for a second laparotomy to receive intralesional injection of $20 \%$ aspirin or physiological saline solution, respectively. The $20 \%$ aspirin solution ( $\mathrm{pH} 7.27$ ) was obtained by diluting $2 \mathrm{~g}$ of acetylsalicylic acid (Pharma Nostra, Brazil) in $10 \mathrm{~mL}$ of $10 \%$ sodium bicarbonate solution. Treatments were administered as $0.2-0.4 \mathrm{~mL}$ aliquots of the experimental or control solution, as this volume was sufficient to infiltrate the entire peritoneal lesion ${ }^{12}$.

The control and aspirin-treated groups were further sub-divided into equal groups for analysis of early (10 days posttreatment, $n=10$ ) and late (20 days post-treatment, $n=10)$ effects. Thus, the four study groups were: control group 1 (10 days); control group 2 (20 days); aspirin-injected experimental group 3 (10 days); and aspirin-injected experimental group 4 (20 days). Animals were sacrificed by intravenous anesthesia overdose.

\section{Clinical evolution}

During the study period (variable according to group), clinical outcomes of all animals were assessed by objective parameters, including recovery from surgery, feeding behavior, and activity, being then classified into good, fair, or poor ${ }^{11}$.

\section{Gross and microscopic analysis}

Immediately upon anesthesia overdose, a third laparotomy was performed for measurement of the length and width in millimeters of each implant ${ }^{12-15}$, evaluation of abdominal and thoracic cavities ${ }^{11}$, and specimen collection (all lesions were removed). Specimens were sectioned and stained with hematoxylin-eosin for histopathological analysis, which was conducted by an experienced pathologist who was blinded to the study. Qualitative analysis was performed by analyzing the histopathological characteristics (endometriosis level, necrosis, bleeding, inflammatory cells infiltrate and apoptosis) of surgical specimens ${ }^{10,16}$. Quantitative analysis was performed by measuring the percentage of total endometriotic tissue represented by tumor cells using the Kontron KS300 V2.0 (Kontron AG, Eching/ München, Germany) imaging software, as previously reported ${ }^{12}$. This computer program measures various shades within the blue, red, or green color spectrums. In the histological sections, endometrial tissue is colored in red; therefore the program, presents data as percent area colored in red, which is then analyzed to demonstrate the total area (in percentage) of endometriotic tissue $^{12}$

\section{Statistical analysis}

For the descriptive analysis, mean and standard deviations were used for metric variables, and percentages were given for categorical variables. To analyze gross area and remaining endometrial tissue, the Kolmogorov-Smirnov test was used to evaluate whether the two variables presented normal distribution (accepting normality for both). Subsequently, two-way analysis of variance was performed for each variable using $\mathrm{F}$ test, to evaluate possible group, time, and group-time interaction effects. Multiple comparisons were made using Tukey's test in the group-time interaction. Variance analysis was performed as data had normal distribution and homogeneity of variances. Thus, analysis of variance followed by Tukey's test has greater power (0.99) than other tests (uniformly most powerful, UMP test). The Statistical Package for Social Sciences (SPSS version 16.0 for Windows, Chicago, IL, USA) was used in all statistical calculations. Values were considered significant at 95\% confidence interval $(p<0.05)$.

\section{Results}

\section{Clinical evolution}

All animals presented good clinical evolution in all three groups. No animal died during the experimental procedures.

\section{Control group 1, 10 days post-treatment}

Macroscopically, all implants formed cystic structures, 4 $(40 \%)$ of which were hemorrhagic. This aspect was confirmed by microscopy, evidencing well-developed endometrial tissue cysts in all $10(100 \%)$ samples.

\section{Control group 2, 20 days post-treatment}

Macroscopically, all implants formed cystic structures, half of which were hemorrhagic. This aspect was confirmed by microscopy, evidencing cystic formation (endometrial tissue cyst) in all $10(100 \%)$ samples, with columnar epithelial lining associated with a stroma of fusiform cells. In $8(80 \%)$ samples, the endometrium was in a proliferative phase; regions with numerous mitosis and a very small quantity of cellular apoptosis were observed, demonstrating that the endometrial tissue was growing freely in this phase (Figure 1). 


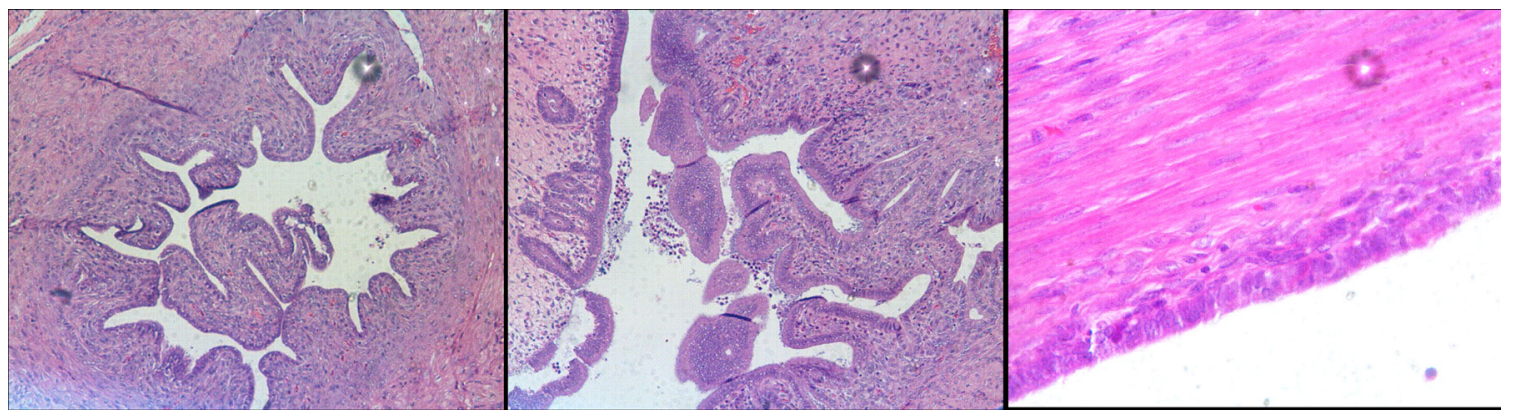

FIGURE 1 - Photomicrograph of histological section from surgical specimen from control group 2 (20 days after saline injection). (Left, center) Peritoneal endometriosis implants with preserved glands and stroma permeated by mild lymphoplasmacytic inflammatory infiltrate and rare eosinophils (Hematoxylen Eosin staining, x100). (Right) Rare and sparse apoptotic corpses (Hematoxylen Eosin staining, x400).

\section{Aspirin-injected experimental group 3, 10 days post-treatment}

All implants observed at the moment of re-operation had a hemorrhagic aspect and adherence to the endometrial cavity content, obstructing visual identification of the macroscopic implant aspect. Microscopy analysis showed small cystic foci of endometrial tissue in all $10(100 \%)$ samples, constituting a smaller aspect compared with the control groups, accompanied by hemorrhage, fibrosis, inflammatory process and apoptosis, without exceptions (Figure 2).

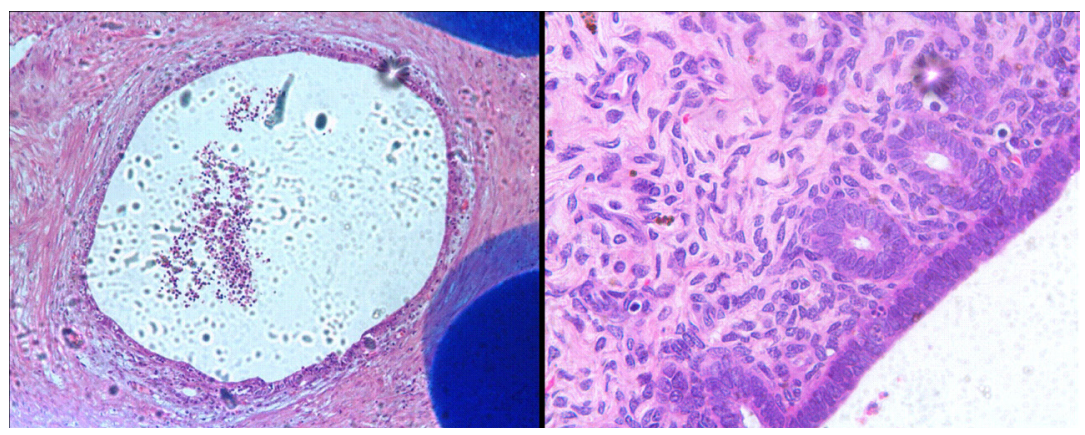

FIGURE 2 - Photomicrograph of histological section from surgical specimen from experimental group 3 (10 days after $20 \%$ aspirin solution injection). (Left) Areas of epithelium and stroma partially preserved permeated by intense lymphocytic and eosinophilic infiltrate (Hematoxylen Eosin staining, $\mathrm{x} 100)$. (Right) Moderate amount of apoptotic corpses and cellular necrosis signs (Hematoxylen Eosin staining, $\mathrm{x} 400$ ).

\section{Aspirin-injected experimental group 4, 20 days post-treatment}

Macroscopically, implants of this group were also difficult to visualize, presenting adherence to the endometrial cavity content. Microscopy was unable to locate cystic formation of endometriosis or evidence of inflammatory process in any of the $10(100 \%)$ analyzed samples, which presented only large areas of necrosis and apoptosis (Figure 3).

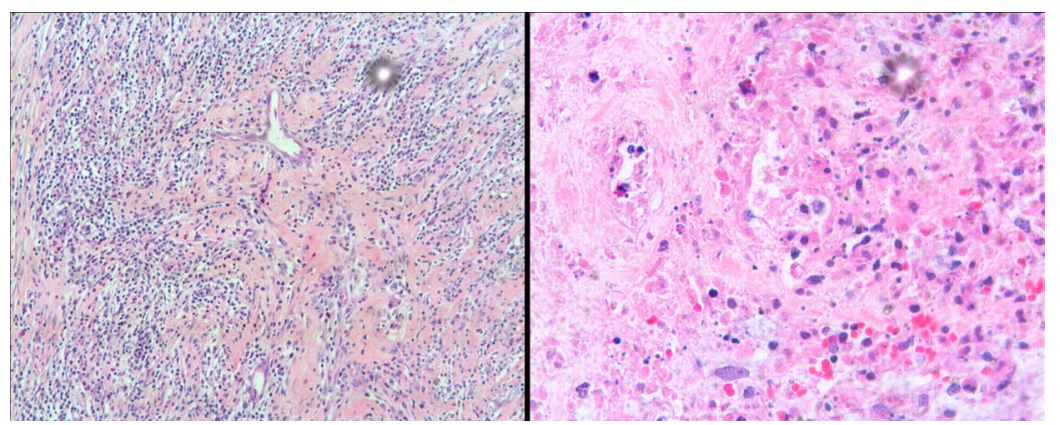

FIGURE 3 - Photomicrograph of histological section from surgical specimen from experimental group 4 (20 days after $20 \%$ aspirin solution injection). (Left) Scar fibrosis areas with proliferation of fibroblasts, collagen fibers, and predominantly mononuclear cells infiltration (Hematoxylen Eosin staining, x100). (Right) Intense inflammatory infiltrate lymphoplasmacytic, glandular and stromal collapse, abundant apoptotic corpses and extensive necrosis (Hematoxylen Eosin staining, x400). 


\section{Gross and histological measurements}

Inter-group comparisons of gross (total endometrial area) and histological (remaining viable endometrial tissue) measurements showed significant $(\mathrm{p}<0.05)$ differences (control groups 1 and $2>$ experimental aspirin-treated group 3, 10 days post-treatment $>$ experimental aspirin-treated group 4, 20 days post-treatment). The rest of the measurements revealed no intragroup significant $(\mathrm{p}>0.05)$ differences (control group $1=$ control group 2) (Table 1).

TABLE 1 - Gross (total endometrial area) and histological (remaining viable endometrial tissue) measurements for each group.

\begin{tabular}{ccc}
\hline Groups & $\begin{array}{c}\text { Gross area } \\
\left(\mathbf{m m}^{\mathbf{2}}\right)\end{array}$ & $\begin{array}{c}\text { Remaining } \\
\text { endometrial } \\
\text { tissue } \\
\mathbf{( \% )}\end{array}$ \\
\hline $\begin{array}{c}\text { Control group 1, 10 days } \\
\text { post-treatment }\end{array}$ & $7044 \pm 732$ & $81 \pm 6$ \\
$\begin{array}{c}\text { Control group 2, 20 days } \\
\text { post-treatment }\end{array}$ & $7065 \pm 1268$ & $83 \pm 8$ \\
$\begin{array}{c}\text { Aspirin-treated group 3, 10 } \\
\text { days post-treatment } \\
\text { Aspirin-treated group 4, 20 } \\
\text { days post-treatment }\end{array}$ & $3585 \pm 857$ & $6 \pm 2$ \\
p-value & $0 \pm 0$ & $0 \pm 0$ \\
\hline
\end{tabular}

Data are presented as mean \pm standard deviation; $d$, days after treatment; ${ }^{*}<0.000$ for all comparisons, except for Control group 1 vs Control group 2 with $\mathrm{p}>0.05$

\section{Discussion}

Endometriosis is defined as the presence of endometrial gland and stromal tissue outside the uterine cavity, such as the ovaries, fallopian tubes, pelvis, among others ${ }^{17,18}$. Of the proposed pathogenic theories (retrograde menstruation, coelomic metaplasia and Müllerian duct remnants), none explain all the different types of endometriosis ${ }^{17}$. According to the most convincing model, the retrograde menstruation hypothesis, endometrial fragments reaching the pelvis via transtubal retrograde flow, implant onto the peritoneum and abdominal organs, proliferate and cause chronic inflammation with formation of adhesions ${ }^{2,17}$. Based on this particular mechanism, primates provide the only animal model that can develop it spontaneously ${ }^{19}$. However, primate models have become limited due to high maintenance cost and innumerable ethical objections ${ }^{19}$. Although there are several animal models for endometriosis research ${ }^{19,20}$, the peritoneal endometriosis rabbit model has been considered as a sufficiently accurate tool for experimental investigations of newly developed treatments, and has been successfully used in studies on histrelin, danazol, levonorgestrel, among others ${ }^{21,22}$. To our knowledge, our study is one of the few reports ${ }^{12}$ to demonstrate the use of this peritoneal endometriosis rabbit model to assess the therapeutic effects of intralesional $20 \%$ aspirin injection.

Acetylsalicylic acid (aspirin) was employed herein due to its generalized use ${ }^{23,24}$ and based on our ${ }^{7-12}$ prior experimental data. The collective results from our in vitro (cultured normal: liver and colonic mucosa of rabbits; VX-2 tumor cells) and in vivo (mesenteric lymph nodes and VX-2 liver tumors) analyses suggest that injecting aspirin directly into liver tumors may destroy the lesion with minimal or no adverse effects, either locally (normal tissue) or systemically ${ }^{7-11}$. In addition, we recently evaluated the effects of intralesional 5\% aspirin injection on peritoneal endometriosis, showing a positive but not completely satisfactory response, as endometriosis foci were only partially destroyed 10 days after treatment ${ }^{12}$. Prior studies ${ }^{13,15,16,25-28}$ with different treatments, such as copper vapor laser, simvastatin, dexamethasone, Uncaria tomentosa (cat's claw), interferon (IFN)- $\alpha-2 b$, celecoxib, rosiglitazone, sunitinib, vitamin D3, $\beta$-Caryophyllene, among others also did not show complete destruction of endometriosis foci.

In this context, it is of paramount importance to acknowledge the definite need for the development of new drugs to provide specific and more efficient therapeutic alternatives to completely eliminate endometriotic lesions, prevent recurrences, and has none or low side effects ${ }^{6}$. Therefore, based on our previously tested different doses and periods of time in other experimental rabbit models ${ }^{7-11}$, the present study was delineated to evaluate whether a higher aspirin concentration and longer follow-up of outcomes (namely, 20\% aspirin and 20 days after intralesional injection, respectively) could positively impact on completely reducing peritoneal endometrial tissue.

Our gross and histological results indicated that the effects of $20 \%$ aspirin injection on experimental group 3 (10 days) were similar to our previous study using $5 \%$ aspirin injection ${ }^{12}$, as there was only partial reduction of endometrial foci. However, results from experimental group 4 (20 days) showed a full response with $20 \%$ aspirin injection, evidenced by total elimination of gross and histological areas of endometriotic tissue, leaving only fibrosis, necrosis, and apoptosis in their place.

In addition, the mean gross and histological areas from aspirin-treated experimental group 4 (20 days) was significantly lower than the aspirin-treated experimental group 3 (10 days). 
This particular result clearly demonstrates the maintenance and increase of the effects of intralesional $20 \%$ aspirin injection without evidence of recurrence, as we have previously demonstrated in a different experimental setting ${ }^{11}$.

In the endometriosis literature, a therapeutic alternative with selective properties only against the ectopic endometrium has not been reported as yet ${ }^{2}$. In fact, as compounds that provide a long disease remission phase are already available for endometriosis, new treatments should ideally eradicate the disease rather than merely relieve its symptoms ${ }^{2}$. Moreover, the pharmacological eradication of ectopic endometrium would convey a high risk of damage to normal endometrial mucosa, with potential consequences to fertility ${ }^{2}$. In this context, we demonstrated that intralesional $20 \%$ aspirin injection produced favorable clinical evolution in all animals, and not associated with animal death, suggesting not only good therapeutic efficacy but also a good safety profile. In addition, the absence of tissue changes (no signs of hemorrhage, inflammation, and/or fibrosis) in the non-operated anatomical areas (i.e., organs and serous membranes of the thoracic and abdominal cavities) indicated that the intralesional $20 \%$ aspirin injection did not cause any damage to proximal pulmonary and/or abdominal tissues, as previously demonstrated in a VX2 hepatic tumor rabbit model ${ }^{11}$. However, surgical tissues resected from aspirin-treated animals showed signs of fibrosis, suggesting that the treated area may differentiate to fibrotic scar tissue. As the scar tissue can negatively impact on local tissue function and culminate in clinical manifestations, further investigations should examine the real scar tissue formation rate and its clinical repercussions (e.g., fertility studies) after intralesional aspirin injection.

Another issue to consider is that it has been well demonstrated that there is an apoptotic dysregulation in the pathophysiology of endometriosis, although it is unlikely that apoptosis per se will explain the whole pathophysiology of endometriosis ${ }^{29-31}$. Thus, as it has been demonstrated that increased cell proliferation and decreased endometrial cell survival and apoptosis facilitate ectopic implantation of endometriotic cells in women with endometriosis ${ }^{29-31}$. Therefore, alternative therapies that induce apoptosis are relevant for the prevention and treatment of this disease. We demonstrated that aspirin-treated sample groups had a higher number of apoptotic cells compared to the control groups, and that there was a progressive increase in apoptosis among the experimental groups (10 days $<20$ days). Prior studies also showed increased apoptotic cells in different tissues (including endometriotic tissue) treated with aspirin or other drugs such as celecoxib, rosiglitazone, sunitinib, vitamin D3, $\beta$-Caryophyllene, among others ${ }^{12,15,16,27,28}$. However, our data demonstrated a correlation between apoptosis increase and complete destruction of experimental peritoneal endometriosis. Previous reports ${ }^{12,15,16.27,28}$ did not show the same correlation.

According to the cancer literature ${ }^{33-36}$, regular intake of nonsteroidal anti-inflammatory drugs and cyclooxygenase (COX) inhibitors, such as aspirin, can reduce the risk of developing some cancers, prevent tumorigenesis, suppress established tumor growth in animals, and inhibit the growth of endometrial cancer cells. In the endometriosis literature, a randomized controlled trial demonstrated a more effective symptom control with the COX2 inhibitor rofecoxib compared with placebo in minimal or mild endometriosis ${ }^{37}$. In addition, the effects of inhibiting COX2 enzyme in in vitro and in vivo endometriosis models have been studied ${ }^{16,38-41}$. A selective COX-2 inhibitor was added to cultured human epithelial endometrial cells and it was found that it inhibited cell proliferation, enhanced cell apoptosis, and diminished vascular endothelial growth factor and prostaglandin $\mathrm{E}_{2}$ secretion ${ }^{16,38-41}$. These COX2 inhibitors have also been used in endometriosis animal models and have demonstrated to prevent the implantation of endometrium to ectopic sites and to induce the regression of endometrial explants ${ }^{16,38-41}$. Therefore, considering that COX-2 overexpression is a frequent finding in ectopic endometrium tissue $\mathrm{e}^{29-31}$, we may assume that the direct injection of aspirin to endometriosis foci may stimulate apoptosis and destroy endometriotic cells (as observed in our experimental study) through a mechanism involving inhibition of COX proteins. Future investigations are important to evaluate inhibition of COX proteins and COX-related pathways in endometriosis.

Potential limitations of our study should be addressed. We did not adopt all existing methods for assessment of histological outcomes, although our measurements were grounded in previously published methods ${ }^{12-15}$. A further limitation is that our study focused solely on one therapeutic agent, and no comparisons were made with similar substances, such as acetic acid or other COX-2 inhibitors. In addition, we did not evaluate the pharmacological parameters (e.g., serum levels of study medication, possible systemic biochemical changes, and concentrations in peritoneal fluid) of the aspirin treatment. Since acetylsalicylic acid is one of the best studied therapeutic substances ${ }^{23,24}$, we chose to focus our current study on its potential benefits as an intralesionallydelivered agent for peritoneal endometriosis. Further experimental studies should not only be designed to overcome these limitations but also to include additional long-term effects of aspirin treatment and different delivery methods (e.g., laparoscopic approach) prior to extending the analysis to humans in a clinical environment. 


\section{Conclusion}

The rabbit model of peritoneal endometriosis was used to show that intralesional $20 \%$ aspirin injection does induce endometriosis destruction within 10 days after treatment, and that the anti-endometriotic effects were maintained and remained significant at 20 days post-injection, with progressive increase of apoptosis and with no signs of endometriotic tissue.

\section{References}

1. Johnson NP, Hummelshoj L; World Endometriosis Society Montpellier Consortium. Consensus on current management of endometriosis. Hum Reprod. 2013;28(6):1552-68. PMID: 23528916.

2. Vercellini P, Viganò P, Somigliana E, Fedele L. Endometriosis: pathogenesis and treatment. Nat Rev Endocrinol. 2014;10(5):26175. PMID: 24366116.

3. Dunselman GA, Vermeulen N, Becker C, Calhaz-Jorge C, D'Hooghe T, De Bie B, Heikinheimo O, Horne AW, Kiesel L, Nap A, Prentice A, Saridogan E, Soriano D, Nelen W; European Society of Human Reproduction and Embryology. ESHRE guideline: management of women with endometriosis. Hum Reprod. 2014;29(3):400-12. PMID: 24435778.

4. Soares SR, Martínez-Varea A, Hidalgo-Mora JJ, Pellicer A. Pharmacologic therapies in endometriosis: a systematic review. Fertil Steril. 2012;98(3):529-55. PMID: 22938768.

5. Guo SW, Hummelshoj L, Olive DL, Bulun SE, D'Hooghe TM, Evers JL. A call for more transparency of registered clinical trials on endometriosis. Hum Reprod. 2009;24(6):1247-54. PMID: 19264712.

6. Streuli I, de Ziegler D, Borghese B, Santulli P, Batteux F, Chapron C. New treatment strategies and emerging drugs in endometriosis. Expert Opin Emerg Drugs. 2012;17(1):83-104. PMID: 22439891.

7. Saad-Hossne R, Prado RG, Hossne WS. Efeito da solução de ácido acetilsalicílico e de ácido acético em fígado de coelhos. Acta Cir Bras. 2004;19(6):677-86. doi: 10.1590/S0102-86502004000600016.

8. Saad-Hossne R, Prado RG, Hossne WS. Effects of acetylsalicylic acid and acetic acid solutions in VX2 carcinoma cells. In vitro analysis. Acta Cir Bras. 2006;21(3):151-4. doi: 10.1590/S010286502006000300006 .

9. Saad-Hossne R, Prado RG, Hossne WS. Effects of acetylsalicylic acid and acetic acid solutions on VX2 liver carcinoma in rabbits: in vivo analysis. Acta Cir Bras. 2007;22(4):299-308. doi: 10.1590/ S0102-86502007000400012.

10. Batista RP, Denadai R, Saad-Hossne R. Effects of aspirin on mesenteric lymph nodes of rabbits as basis for its use on lymph nodes metastases. Acta Cir Bras. 2012;27(11):795-801. PMID: 23117612.

11. Saad-Hossne R, Teixeira FV, Denadai R. In vivo assessment of intratumoral aspirin injection to treat hepatic tumors. World $\mathrm{J}$ Hepatol. 2013;5(7):372-8. PMID: 23898370.

12. Siqueira JM, Barretto AB, Saad-Hossne R. Treatment of endometriosis with local acetylsalicylic acid injection: Experimental study in rabbits. J Minim Invasive Gynecol. 2011;18(6):800-6. PMID: 22024267.

13. Ingelmo JM, Quereda F, Acién P. Intraperitoneal and subcutaneous treatment of experimental endometriosis with recombinant human interferon-alpha-2b in a murine model. Fertil Steril. 1999;71(5):90711. PMID: 10231055.
14. Somigliana E, Viganò P, Rossi G, Carinelli S, Vignali M, PaninaBordignon P. Endometrial ability to implant in ectopic sites can be prevented by interleukin-12 in a murine model of endometriosis. Hum Reprod. 1999;14(12):2944-50. PMID: 10601076.

15. Abbas MA, Disi AM, Taha MO. Sunitinib as an anti-endometriotic agent. Eur J Pharm Sci. 2013;49(4):732-6. PMID: 23747661.

16. Olivares C, Ricci A, Bilotas M, Barañao RI, Meresman G. The inhibitory effect of celecoxib and rosiglitazone on experimental endometriosis. Fertil Steril. 2011;96(2):428-33. PMID: 21683949.

17. Burney RO, Giudice LC. Pathogenesis and pathophysiology of endometriosis. Fertil Steril. 2012;98(3):511-9. PMID: 22819144.

18. Denadai R, Toledo AP, Raposo-Amaral CE. Spontaneous cutaneous endometriosis: a diagnostic challenge in plastic surgery. Aesthetic Plast Surg. 2013;37(2):483-4. PMID: 23361955.

19. Grümmer R. Animal models in endometriosis research. Hum Reprod Update. 2006;12(5):641-9. PMID: 16775193.

20. Silva JC, Silva AC, Coltro PS, Garcia SB, Reis FC, Nogueira AA. Experimental endometriosis model in rabbits with follow-up of lesions. Rev Bras Ginecol Obstet. 2004;26(9):715-9. doi: 10.1590/ S0100-72032004000900007.

21. Hahn DW, Carraher RP, Foldesy RG, McGuire JL. Development of an animal model for quantitatively evaluating effects of drugs on endometriosis. Fertil Steril. 1985;44(3):410-5. PMID: 3896862.

22. Yuan $\mathrm{P}$, Huang $\mathrm{Y}, \mathrm{Wu} \mathrm{H}$, Teng $\mathrm{Z}$, Zhang J, Xin X. Induction of a local pseudo-pregnancy via levonorgestrel-loaded microspheres for the treatment of endometriosis in a rabbit model. Hum Reprod. 2010;25(2):462-9. PMID: 19897855.

23. Berger JS, Lala A, Krantz MJ, Baker GS, Hiatt WR. Aspirin for the prevention of cardiovascular events in patients without clinical cardiovascular disease: a meta-analysis of randomized trials. Am Heart J. 2011;162(1):115-24.e2. PMID: 21742097.

24. Rothwell PM, Fowkes FG, Belch JF, Ogawa H, Warlow CP, Meade TW. Effect of daily aspirin on long-term risk of death due to cancer: analysis of individual patient data from randomised trials. Lancet. 2011;377(9759):31-41. PMID: 21144578.

25. Nogueira Neto J, Lindoso MJ, Coelho LF, Carvalho RA, Rodrigues TG, Araújo AG, Girão MJ, Schor E. Changes in the volume and histology of endometriosis foci inrats treated with copaiba oil (Copaiferalangsdorffii). Acta Cir Bras. 2011;26 Suppl 2:20-4. PMID: 22030810.

26. Nogueira Neto J, Coelho TM, Aguiar GC, Carvalho LR, de Araújo AG, Girão MJ, Schor E. Experimental endometriosis reduction in rats treated with Uncaria tomentosa (cat's claw) extract. Eur J Obstet Gynecol Reprod Biol. 2011;154(2):205-8. PMID: 21030132.

27. Abbas MA, Taha MO, Disi AM, Shomaf M. Regression of endometrial implants treated with vitamin D3 in a rat model of endometriosis. Eur J Pharmacol. 2013;715(1-3):72-5. PMID: 23810684.

28. Abbas MA, Taha MO, Zihlif MA, Disi AM. $\beta$-Caryophyllene causes regression of endometrial implants in a rat model of endometriosis without affecting fertility. Eur J Pharmacol. 2013;702(1-3):12-9. PMID: 23353590.

29. Taniguchi F, Kaponis A, Izawa M, Kiyama T, Deura I, Ito M, Iwabe T, Adonakis G,Terakawa N, Harada T. Apoptosis and endometriosis. Front Biosci (Elite Ed). 2011;3:648-62. PMID: 21196342.

30. Reis FM, Petraglia F, Taylor RN. Endometriosis: hormone regulation and clinical consequences of chemotaxis and apoptosis. Hum Reprod Update. 2013;19(4):406-18. PMID: 23539633.

31. Garcia-Velasco JA, Arici A. Apoptosis and the pathogenesis of endometriosis. Semin Reprod Med. 2003;21(2):165-72. PMID: 12917786.

32. Iwata C, Kano MR, Komuro A, Oka M, Kiyono K, Johansson E, Morishita Y, Yashiro M, Hirakawa K, Kaminishi M, Miyazono K. Inhibition of cyclooxygenase-2 suppresses lymph nodemetastasis via 
reduction of lymphangiogenesis. Cancer Res. 2007;67(21):10181-9. PMID: 17974958.

33. Yu HG, Huang JA, Yang YN, Huang H, Luo HS, Yu JP, Meier JJ, Schrader H, Bastian A,Schmidt WE, Schmitz F. The effects of acetylsalicylic acid on proliferation, apoptosis, and invasion of cyclooxygenase- 2 negative colon cancer cells. Eur J Clin Invest. 2002;32(11):838-46. PMID: 12423325.

34. Gao J, Niwa K, Sun W, Takemura M, Lian Z, Onogi K, Seishima M, Mori H, Tamaya T. Non-steroidal anti-inflammatory drugs inhibit cellular proliferation and upregulate cyclooxygenase-2 protein expression in endometrial cancer cells. Cancer Sci. 2004;95(11):9017. PMID: 15546508.

35. Arango HA, Icely S, Roberts WS, Cavanagh D, Becker JL. Aspirin effects on endometrial cancer cell growth. Obstet Gynecol. 2001;97(3):423-7. PMID: 11239649.

36. Cobellis L, Razzi S, De Simone S, Sartini A, Fava A, Danero S, Gioffrè W, Mazzini M,Petraglia F. The treatment with a COX-2 specific inhibitor is effective in the management of pain related to endometriosis. Eur J Obstet Gynecol Reprod Biol. 2004;116(1):1002. PMID: 15294376.

37. Matsuzaki S, Canis M, Darcha C, Dallel R, Okamura K, Mage G. Cyclooxygenase-2 selective inhibitor prevents implantation of eutopic endometrium to ectopic sites in rats. Fertil Steril. 2004;82(6):1609-15. PMID: 15589867.

38. Ozawa Y, Murakami T, Tamura M, Terada Y, Yaegashi N, Okamura $\mathrm{K}$. A selective cyclooxygenase-2 inhibitor suppresses the growthof endometriosis xenografts via antiangiogenic activity insevere combined immunodeficiency mice. Fertil Steril. 2006;86(4 Suppl):1146-51. PMID: 16962108.

39. Dogan E, Saygili U, Posaci C, Tuna B, Caliskan S, Altunyurt S, Saatli B. Regression of endometrial explants in rats treated with the cyclooxygenase-2 inhibitor rofecoxib. Fertil Steril. 2004;82 Suppl 3:1115-20. PMID: 15474083.

40. Olivares C, Bilotas M, Buquet R, Borghi M, Sueldo C, Tesone M, Meresman G. Effects of a selective cyclooxygenase-2 inhibitor on endometrial epithelial cells from patients with endometriosis. Hum Reprod. 2008;23(12):2701-8. PMID: 18716040.
41. Xiaoxin M, Yingnan J, Yanxia L, Shu L, Yuanqi H, Hongwei L. Experimental research on the depressant effect of aspirin on Ishikawa adenocarcinoma endometrium cell growth. Int J Gynecol Cancer. 2009;19(7):1182-5. PMID: 19820387.

\section{Acknowledgement}

To Profa. Maria Aparecida Marchezan Rodrigues for her histopathological support.

\section{Correspondence:}

Rogério Saad-Hossne

Faculdade de Medicina de Botucatu, UNESP

Distrito de Rubião Júnior, $\mathrm{s} / \mathrm{n}$

18618-000 Botucatu - SP Brasil

Tel./Fax: (55 14)3882-5475

saad@fmb.unesp.br

Received: Dec 15, 2015

Review: Feb 11, 2016

Accepted: Mar 14, 2016

Conflict of interest: none

Financial source: FAPESP (No 2010/00552-5)

${ }^{1}$ Research performed at Laboratory of Experimental Surgery, Department of Surgery, Botucatu Medical School (FMB), Universidade Estadual de São Paulo (UNESP), Botucatu-SP, Brazil. Part of Master degree thesis, Postgraduate Program in General Bases of Surgery, FMB-UNESP. Tutor: Rogério Saad-Hossne. 